\title{
Avaliação educacional em larga escala: a opção pela democracia participativa ${ }^{1}$
}

\author{
Educational assessment in large scale: the choice of participatory \\ democracy
}

\section{Daianny Madalena Costa²}

\section{Resumo:}

A ideia de desenvolver um trabalho que dialogue sobre as políticas educacionais, num recorte da avaliação de larga escala, levando em conta os pilares da regulação e da emancipação, remete à opção pela democracia participativa. Fortalecê-la dentro das condições favoráveis para que seus atores se sintam efetivamente construtores de uma escola que lhe diga respeito, é tarefa de uma política educacional que prime pela democracia participativa, como ferramenta na construção de um Estado preocupado em gerar qualidade na educação. Afinal, muitos são os índices que demonstram o fracasso da instituição escolar, porém, não as atrelam, às políticas também protagonizadas pelos mesmos autores. A falta de participação gerou a lógica de especialistas que criam e recriam políticas a ser implementadas no contexto escolar, um Estado regulado pelo mercado, ou ainda de um quase-mercado. Por isso, o envolvimento nos destinos da educação é uma maneira viável de reequilibrar as forças advindas do mercado, contrabalançando ao Estado e à comunidade. Investir na democracia participativa, como caminho possível de maior integração entre todos os participantes do mesmo cenário.

Palavras-chave: política educacional, regulação, emancipação, avaliação de larga escala e democracia participativa.

\begin{abstract}
:
The idea of developing a work that dialogue on educational policies, a clipping of the largescale assessment, taking into account the pillars of regulation and emancipation refers to the choice of participatory democracy. Strengthen it in the favorable conditions for the actors to feel actually manufacturers a school that it is concerned, is the task of an educational policy that excels in participatory democracy as a tool in the construction of a state concerned to bring about quality education. After all, there are many signs showing the failure of the school, but not the particular relationship, the policies also played out by the same authors. The lack of participation led to the logic of specialists who create and recreate policies to be implemented in the school context, a state governed by the market, or a quasi-market. Therefore, the involvement in the destiny of education is a viable way to balance the forces resulting from the market, offsetting the state and the community. Investing in participatory democracy, as a possible path to greater integration between all participants in the same scenario.
\end{abstract}

Key-words: educational policy, regulation, empowerment, evaluation of large-scale and participatory democracy.

1 Este trabalho compõe parte da Tese de Doutorado que desenvolvo sob Orientação da Professora Dr. ${ }^{a}$ Flávia Obino Corrêa Werle com base em uma pesquisa intitulada Gestão Democrática e Qualidade da Educação Básica, com financiamento do Edital 1/2006 do Instituto Nacional de Estudos e Pesquisas Educacionais Anísio Teixeira (INEP), Coordenação de Aperfeiçoamento de Pessoal de Nível Superior (CAPES) e Observatório de Educação, que prevê a ampliação da produção acadêmica a partir das bases de dados do INEP e a formação de recursos humanos capacitados para a gestão de políticas educacionais, avaliação e formação de docentes.

2 Doutoranda do Programa de Pós-Graduação da Unisinos. E-mail: daiannycosta@hotmail.com 
Inicialmente, em nome da abertura dos mercados e do sonho de fazer parte do primeiro mundo, países subdesenvolvidos se lançaram a referendar o projeto neoliberal, que, em última análise, promove o individualismo e a competitividade. Mais tarde, com as crises enfrentadas pela economia mundial devidas ao insucesso das suas iniciativas e convicções, esses países não lograram entrar para o grupo de países de primeiro mundo, nem, tampouco, conquistar melhorias na qualidade de vida de seus habitantes. Esse projeto, portanto, enfrentou um profundo colapso, o que lançou esses países na busca de novas alternativas. Devido ao fracasso de sua experiência neoliberal, coubeIhes, portanto, a busca de novos "modelos" de inclusão social, justiça e democracia.

No contexto atual, as rápidas e profundas transformações econômicas, políticas e sociais, em curso por todo o planeta, fazem com que os países enfrentem reivindicações de diversas ordens, como por exemplo: étnicas, de gênero, por segurança etc. Os movimentos que surgem pela paz, o aprofundamento da desigualdade e os dilemas da consolidação democrática, colocaram a questão da educação como mobilizadora das melhores energias e criatividade para a construção de um mundo diferente, mais humano e solidário.

Depreende-se daí uma grande indagação: se é o Estado quem tem o dever de promover o bem estar de seu povo, qual será o novo paradigma que terá o condão de proporcionar esta promoção?

A política, assim como outros tantos temas, possui uma multiplicidade de entendimentos, que foram reinterpretados e redimensionados no decorrer da história. Nós, no entanto, compreendemos que enquanto campo de estudo esta se ocupa em compreender as atividades humanas articuladas às coisas do Estado (Shiroma, 2000).

Daí que para essa pesquisadora (ibid) o conceito política está atrelado ao poder do Estado, por isso, em permanente tensão, pois a sociedade organizada, suas representações, instituições e sua organização compõem o ente Estatal. Nunca sem conflitos, pelo contrário, em constante jogo de interesses e ideias.

A política é ao mesmo tempo ato de disputa e decisão. Assim, o resultado de uma política pública, por exemplo, é produzido a partir de muitos conflitos até que seja construído. Disputa e decisão, por isso, são representações que compõem a própria produção de uma política pública, exigindo, permanentemente, atenção ao seu entorno, pois, se vários são os sujeitos políticos, consequentemente muitos serão os textos e os contextos (Mainardes, 2006) que servirão à promoção da política pública como fora pretendida efetivamente por esses sujeitos políticos.

Na permanente correlação de forças, existente entre os diversos atores que disputam e decidem sobre a política, é que vemos, muitas vezes, reformas sucumbirem, porque não levaram em conta nem minimamente os entes que compõem o cenário que estará prestes a ser modificado.

$\mathrm{Na}$ intenção de compreender a formulação política educacional - enquanto produto do "jogo" político e sustentada em projetos que dialoguem com a sociedade e que componham objetivos que se (re)contextualizam no cenário da educação nacional, é que desenvolvemos esta etapa do estudo. Afinal a educação é realizada a partir da política e é, por isso, configurada enquanto um ato político (Gadotti, Freire e Guimarães, 2000).

Como não poderia ser diferente, o momento histórico que vivemos não está desarticulado dos já vividos. É por este motivo que nos debruçamos a pensar sobre as possibilidades de construirmos saídas aos modelos criados pelo liberalismo econômico. Ter clareza de que nos movemos ainda por dentro do paradigma dominante, é uma possibilidade viável de recriação (Costa, 2008), e nisto, reside o fazer político.

Quanto mais vemos ruir os princípios que estabeleceram a forma com que atualmente a sociedade se organiza, mais evidente se torna a necessidade de recriarmos estes princípios, a conveniência de que a política educacional responda eficientemente à oportunidade viável de sua reinvenção.

A crise mundial na qual estamos inseridos afeta, logicamente, as estruturas que alicerçam o paradigma dominante e, em última instância, consequentemente, a educação. A internacionalização das políticas educacionais, é factível, sofrerá uma forte contraposição a favor da transformação social e do paradigma 
emergente, liadas à luta anti-imperialista, a favor da igualdade e da paz.

A tensão está colocada. Não é novidade que as políticas de educação básica, para serem eficientes, devam contemplar adequadamente as especificidades socioculturais locais e que o poder sobre as decisões relativas aos conteúdos e às dinâmicas escolares deve ser compartilhado com a comunidade local, essa ideia está sólida e explicitamente incorporada em documentos internacionais, como a Declaração de Nova Delhi "Educação Para Todos", ou o relatório "Educação um tesouro a descobrir", de Jacques Delors que estabelece os quatro pilares da educação contemporânea: aprender a ser, a fazer, a viver juntos e a conhecer e que constituem aprendizagens imprescindíveis que precisam ser incorporadas de forma permanente pelas políticas educacionais de todos os países.

Edgar Morin, (2000) ${ }^{3}$, traz uma crítica prudente ao modelo de globalização vivido pela humanidade hoje, que exclui bilhões de vidas humanas. Mas não se resume às vidas humanas, todo o ecossistema, por exemplo, tem sido vitimado pelo modelo. O aponta para a construção de uma consciência humana baseada na unidade/diversidade enquanto processo dialógico de um Planeta mais pleno e feliz.

É oportuno ainda mencionar o aumento da consciência política como mola propulsora da participação dos sujeitos envolvidos efetivamente na educação, promovendo projetos hegemônicos a favor da escola pública democrática e participativa (PARO, 2002).

Ficam explícitos os conflitos existentes entre os paradigmas dominante e emergente. $\mathrm{O}$ primeiro propõe para a educação a ampliação do número de vagas, maior permanência na escola, mas não responde à transformação efetiva da vida dos alunos, da comunidade, não democratiza o conhecimento, não responde pedagogicamente sobre a inserção do estudante naquele dado lugar; esta é tarefa que se coloca ao paradigma emergente. Naquele, o viés da educação é administrativo e economicista, fazer o "melhor" como "menor preço"; neste o objetivo é aprofundar a discussão sobre que escola é necessária e para quem? Conclama a comunidade para discutir efetivamente sobre esta possibilidade, uma escola que efetive a construção do conhecimento, da cidadania de sujeitos engajados em sua história e transformadores do seu cotidiano.

Uma boa política educacional, a favor da construção do paradigma emergente, pode ser viável, se na sua elaboração levar em conta uma maior participação daqueles que estão efetivamente envolvidos no cotidiano da escola. Se, sua formulação contar, portanto, com a existência de conflitos e tensões, produzindo respostas àquilo que se espera da escola, levando em conta para quem e para que esta serve e qual a sua função social. Os sujeitos escolares, por certo, têm competência para essa elaboração, não tendo que esperar especialistas que forneçam fórmulas mágicas de uma política decente para a comunidade escolar. E mais, não se pode cometer a ingenuidade de pensar que estes 'especialistas' são sujeitos acima do bem e do mal, sem interesses políticos e/ou econômicos.

Por tudo isso, compreender os processos de emancipação na justaposição ao domínio da regulação requer que concebamos a possibilidade de transformação do paradigma capitalista liberal que investe prioritariamente na competição, para outra direção, qual seja, a oportunidade de homens e mulheres conviverem solidariamente, igualmente e emancipados nos espaços que povoam.

A humanidade vem experimentando formas de convivência. Estamos longe da harmonia, do reconhecimento da plenitude da vida para todos, mas já chegamos a patamares importantes de consciência do outro.

É justamente a possibilidade de convivermos mais harmonicamente que nos leva a pensar numa outra política educacional, mais comprometida 
com a felicidade, com o bem estar, com a dignidade de todos. Agindo diferentemente, estaríamos reforçando os velhos princípios do liberalismo que vêm vigendo há muito tempo.

A esperança de que seremos capazes de nos compreendermos, uno e coletivo, faz com que possamos compartilhar a vida do outro, culturalmente tão diferente. Porém, reconhecer que a diferença não significa desigualdade, pelo contrário, a viabilidade de que todos tenham as mesmas condições e necessidades sanadas, move-nos na perspectiva de compartilharmos nosso conhecimento.

Quando consideramos os termos 'cultura das humanidades', é preciso pensar a palavra 'cultura', em seu sentido antropológico: uma cultura fornece os conhecimentos, valores, símbolos que orientam e guiam as vidas humanas. A cultura das humanidades foi, e ainda é, para uma elite, mas de agora em diante deverá ser para todos, uma preparação para a vida (MORIN, 2001, p. 48).

A crítica que fazemos ao Estado liberal é justamente de que, não obstante tenha sido criado para proporcionar mais justiça e igualdade, serviu para o usufruto de poucos, preconizando o ideal da competição e do individualismo como naturalização da vida e da cultura humana.

Reportamo-nos a Adam Smith quando produziu uma das suas obras mais consagradas, A Riqueza das Nações, em 1776, na qual encontramos os princípios da economia liberal como, por exemplo, concorrência e individualismo que compõem também a lógica inserida no universo escolar, reforçando, com isso, a ideia de que a escola é uma ferramenta dos grupos dominantes que compõem a sociedade.

(...) quando a concorrência é livre a rivalidade entre os concorrentes que, sem exceção, se empenham em eliminar-se mutuamente do emprego, obriga cada um a procurar executar seu trabalho com certo grau de precisão. (...) A rivalidade e a emulação tornam 0 mérito, mesmo nas profissões mais humildes, objeto de ambição, gerando muitas vezes os mais satisfatórios empenhos. (SMITH, 1983, p. 200).

A ênfase dada por Smith à competição tornase "marca registrada" do modelo liberal. Para uma produção cada vez maior, cabe o incentivo exagerado à rivalidade entre as pessoas.
As crises vividas pelo capitalismo originaram o neoliberalismo e, inicialmente, viabilizaram o Estado de Bem-estar Social como forma de manter a lógica capitalista e sua provável hegemonia, dada à disputa instaurada com o modelo Socialista que estava instalando-se em alguns países.

O Estado de Bem-estar Social ou de Providência demonstrou seu desgaste ao longo das décadas de 1950 e 1960, em relação a uma burguesia voraz, que ao fim e ao cabo, necessitava ressuscitar os princípios mais importantes do capitalismo.

Para isto, as empresas estatais concebidas no Estado de Bem-Estar Social, passam a ser privatizadas, resguardando uma nova faceta do capitalismo que enfatiza a regulação do Estado a partir das regras traçadas pelo mercado econômico. Noutras palavras, podemos afirmar que o mercado passa a ser a própria mão visível do Estado.

As consequências imediatas das privatizações se refletem no dia a dia das pessoas, já que as empresas estatais vendidas perdem imediatamente 0 seu caráter político-social. Doravante só um mote as move: o lucro. Para isso dispensam funcionários, aumentam tarifas e constroem monopólios privados, cognominados de economia de mercado. (RAMPINELLI, 2001, p. 23) [grifos do autor].

A ideia de que o Estado cumpre com as imposições do mercado também é prerrogativa do liberalismo. Clarck, (2008), pondera sobre a simbiose existente entre mercado e Estado ao longo da lógica liberal, lembremos, por exemplo, do período mercantil europeu. Assim, o Estado ora dilata sua intervenção no domínio econômico, ora a restringe, mas sempre em decorrência do mercado.

Atualmente, o estado democrático de Direito do século XXlage 'contidamente' navidaeconômica, por intermédio da política econômica de regulação, diferentemente dos tempos do Estado Social do século XX, onde aquela era chamada de regulamentação e a atuação pública foi mais aguda. Contudo, historicamente, o Estado sempre agiu na vida econômica de diferentes formas e intensidades (CLARK, 2008, p. 6).

O que caracteriza, portanto, a nova etapa do capitalismo, denominada neoliberalismo, é uma regulação estatal ditada pelo mercado econômico. Barroso corrobora, trazendo o 
conceito de regulação, ao qual nos filiamos, buscando o sentido utilizado pela economia que serve para identificar a intervenção de instâncias com legitimidade, que orientam e coordenam as ações dos agentes econômicos. (p. 3).

Para Afonso Janela, (2005) a década de 1980 foi o auge da reconstrução do modelo neoliberal, por meio do neoconservadorismo e do neoliberalismo que afirmaram os pressupostos básicos $\mathrm{e}$ elementares da origem do pensamento liberal ( $p$. 44) assegurando o Estado enquanto Avaliador.

Esta expressão quer significar, em sentido amplo, que 0 Estado vem adoptando um ethos competitivo, neodarwinista, passando a admitir a lógica do mercado, através da importação para o domínio público de modelos de gestão privada, com ênfase nos resultados ou produtos dos sistemas educativos. ( $p$. 49) [grifo do autor].

Em última instância podemos afirmar, portanto, que o neoliberalismo hegemoniza os princípios mais autênticos do liberalismo, aprofundando, consequentemente, a regulação, ou seja, que as políticas do Estado deem conta de regular a vida da sociedade para que o modelo capitalista possa operar livremente.

Neste sentido Boaventura S. Santos (2001), estimulado a contribuir com a compreensão sobre os processos de crise e interpretação vividos no final do século XX, convoca-se a desenvolver uma possível hermenêutica crítica da epistemologia dominante, acreditando que o direito e a ciência modernos contribuíram para a absorção do pilar da emancipação pelo da regulação (p. 55).

É possível o entendimento de que isto aconteceu, porque, ao invés do desenvolvimento harmônico entre os três princípios da regulação - Estado, mercado e comunidade - houve a predominância do mercado em detrimento dos demais (ibid, p. 56).

Desde a primeira vaga industrial - com a expansão das cidades comerciais e 0 aparecimento de novas cidades industriais no período do capitalismo liberal - até 0 espetacular desenvolvimento dos mercados mundiais - com 0 aparecimento dos sistemas de produção de dimensão mundial, a industrialização do Terceiro Mundo e a emergência de uma ideologia mundial de consumismo no actual 'capitalismo desorganizado' -, o pilar da regulação sofreu um desenvolvimento desequilibrado, orientado para o mercado (ibid p. 56-7).
Dalila Andrade Oliveira (2005), ao dialogar com as reflexões oferecidas por Boaventura de S. Santos que enfatizam a imposição da globalização hegemônica ao mundo, um ritmo muito mais intenso de produção e reprodução das lógicas liberais, por consequência a todo o conjunto da sociedade (p. 05). A autora traz uma compreensão do que vem a ser a ruptura existente frente à regulação moderna, que buscou prioritariamente a expansão capitalista.

Quando esse autor destaca, como um segundo fator novo a voracidade com que a globalização hegemônica tem devorado não só as promessas de progresso, de liberdade, de igualdade, de não discriminação e de racionalidade, como também a própria ideia da luta por elas, está falando de um tipo de desenvolvimento e acumulação capitalista. (ibid, 2005, p. 05).

Estas razões dominam a crença de que o pilar da dominação fora cooptado pela regulação, que desenvolveu uma sociedade calcada no individualismo, no consumo, na valorização do conhecimento científico como forma única de exercer a emancipação, ou seja, essa regulação transformou o cidadão em um voraz consumidor.

O desafio colocado até aqui é o de perceber as rupturas que vêm acontecendo no paradigma dominante a partir da decadência das suas certezas. Essa é uma alternativa viável que nos possibilita recriar os pilares emancipação e comunidade, para que possam efetivamente contribuir com a geração de uma vida mais plena para todos. Este paradigma Boaventura S. Santos (2001) chama de emergente (p. 74).

Eu falarei do paradigma de um conhecimento prudente para uma vida decente. Com esta designação, quero significar que a natureza da revolução científica que atravessamos é estruturalmente diferente da que ocorreu no século XVI. Sendo uma revolução científica que ocorre numa sociedade ela própria revolucionada pela ciência, o paradigma a emergir dela não pode ser apenas um paradigma cientííico (0 paradigma de um conhecimento prudente), tem de ser também um paradigma social (o paradigma de uma vida decente). (ibid, p. 74) [grifos do autor].

Na perspectiva de fortalecermos o paradigma emergente que atenderá a uma equalização entre os princípios da regulação e emancipação, cremos que para a concretude desse ideal, 
conforme aponta o editorial do Caderno Le Monde

Diplomatique (2001), quando da realização do Fórum Mundial e Social, é necessário romper com o neoliberalismo é investir numa democracia participativa (p. 03).

Ocupar-nos-emos agora em considerar a imprescindibilidade de fortalecermos o princípio da emancipação, enquanto empoderamento da sociedade organizada, para que as rupturas já percebidas no paradigma dominante deem lugar ao paradigma emergente.

O Estado só poderá ser efetivamente democrático quanto mais a sociedade democrática o empurrar para este devir, fora disso não o será. Uma sociedade democrática é aquela que se apropria do direito de participar do poder político e social e constrói efetivamente um Estado do qual ela se sente parte.

Nesta argumentação, portanto, apontamos para aexistência deumEstado efetivamente democrático, quando estiver balizado pela participação popular. Para isto, será necessário que a sociedade organizada também se queira democrática, ou seja, só participará se compreender que a democracia é fundamental para qualificarmos a nossa própria vida em comunidade.

É neste sentido que Santos (2001) aponta para emancipações, que ao fim e ao cabo, estarão impossibilitando o Estado de transformar as modificações, sejam elas quais forem, em regulações.

Seja como for, à medida que a transição paradigmática progredir, as lutas emancipatórias deixarão de combater as formas de regulação social que agora existem para combaterem as novas formas de regulação, entretanto surgidas das próprias lutas emancipatórias paradigmáticas. (p. 334).

A crítica instaurada no seio da sociedade capitalista em relação à péssima qualidade da educação escolar, frente aos problemas relativos aos baixos níveis de aprendizagem, dimensiona o descontentamento generalizado com esta instituição. Prova disso são os constantes ataques realizados pela mídia que precisam, em nome do neoliberalismo, deflagrar a ineficiência do sistema educacional. Isto juntamente com a intenção de verificar a incapacidade da escola pública (leia-se Estado) em cumprir sua tarefa básica, já que os índices de evasão, repetência, analfabetismo entre outros, demonstram que a escola não consegue servir nem ao menos para garantir sua função mais primária, qual seja, ensinar as letras e os números.

É provável que o termo avaliação seja um dos mais polêmicos para a educação, pois, decididamente, engendra visões de mundo e postura política, confirmando sua dimensão ideológica e de disputa ao longo da história educacional. Afonso (2005) reflete sobre uma sociologia das políticas avaliativas e constrói o argumento de que "nas escolas, enquanto contexto meso-político, as decisões em torno dos processos avaliativos são também, com frequência, o resultado de jogos de poder e de processos de negociação" (p. 20).

Os Sistemas de Avaliação - estandardizados criados após 1980 cumprem a tarefa de divulgar paraasociedade civilos níveis de desenvolvimento e qualidade da educação. Marcela Gajardo e Jeffrey Puryear (in BONEMY, 1997) co-diretoras do PREAL (Programa de Promoção da Reforma Educativa da América Latina e do Caribe) expõem que estes instrumentos de avaliação publicizam aos pais, professores, empresários, mídia e demais atores sociais, a situação atual da educação escolar, bem como onde estão e quem são as melhores instituições de ensino.

Com isto, é possível que se incremente a qualidade educacional. Assim, quanto mais à comunidade conhecer a efetiva produção escolar, mais poderá se comprometer com sua melhoria, contribuindo para a aprendizagem de seus conteúdos. Porém, a utilização competitiva que dá fim aos resultados conquistados após as avaliações e divulgados pelos órgãos responsáveis por sua realização, balizam os procedimentos posteriores a ela, dando consequência às diversas opiniões sobre a educação e à regulação pelo mercado.

Mello (2004) ao analisar o Relatório Mundial de 1997 (RDM) verificou que o mesmo justifica a importância das avaliações, para que, a partir delas, sejam possíveis estímulos à competição entre os serviços de educação escolar. Isto poderia ajudar a explicar as interferências dos organismos internacionais (Banco Mundial, FMI, 
UNESCO e CEPAL) na definição das políticas públicas dos países que estão engendrados nos princípios do Consenso de Washington.

Medir para concorrer, para rivalizar. Este ao fime ao cabo é o ideal preconizado pelo neoliberalismo e que passa a ser imposto por meio dos seus organismos. Disso resultará a excelência e a credibilidade da educação escolar, que formará sujeitos cada vez mais competitivos.

Neste sentido, o estudo feito por Bonamino (2002) contribui imensamente para a compreensão das políticas de avaliação de larga escala, iniciando com a abrangência dos antecedentes internacionais que deram origem à massificação deste projeto educacional. Investiga os processos ocorridos nos países industrializados (Estados Unidos, Grã-Bretanha e França) que protagonizaram o desenvolvimento de surveys educacionais empregados por estas nações, no apogeu do Estado de Bem-Estar social, vivido no pós-guerra.

Em que pese as diferenças ideológicas que orientaram a utilização destas investigações por estes países, a busca originária era equacionar as desigualdades educacionais por meio dos trabalhos desenvolvidos após os surveys. A autora contextualiza as principais abordagens que forjaram a política educacional do Estado de Providência, ou seja, a Sociologia das desigualdades, a Nova Sociologia da Educação (NSE) e a Teoria da Reprodução, que buscaram a compreensão das desigualdades educacionais que marcavam a vida escolar nos sistemas educacionais elencados.

Apoiados nos dados fornecidos pelas pesquisas de levantamento, a sociologia das desigualdades educacionais, sob inspiração funcionalista, as teorias da reprodução e a NSE, sob inspiração marxista, foram solidárias no reconhecimento de que as desigualdades no desempenho escolar não incidem de maneira aleatória em relação à origem sociocultural dos alunos, atingindo de forma maciça, as crianças dos meios populares. (ibid, p. 33).

A avaliação guarda possibilidades efetivas para que seja viável a qualificação. É necessário, por isso, clareza com o que se quer dela. Assim será possível realizar uma investigação avaliativa e traçar um processo de fazeres que contribuam para o alcance daquilo que efetivamente precisa ser melhorado.

Franco (2004) acredita que a avaliação de larga escala, não como aferição, mas como uma relação complexa de diversos construtos ( $p$. 46), diferenciando, posteriormente, "medidas cognitivas e medidas contextuais" (p. 49), estando em sintonia com a política educacional, é uma medida importantíssima na direção da qualificação do sistema de ensino.

Porém, já vimos que não há uma unanimidade do que se quer com a educação escolar. Daí que Apple, ao estudar o método de avaliação realizado com os professores, aponta seu caráter muito mais punitivo que sugestivo, quanto aos tipos de práticas que poderiam ser adotadas para melhorar as questões pedagógicas que envolvem o ensino. Assim, parece-nos que uma avaliação voltada para o controle também exclui o compromisso com a qualidade, fortalecendo a lógica da aferição a partir da banalização dos números, notas, porcentagens e intensificando a competição.

Garantir um Sistema Público mais eficiente, na linguagem neoliberal, é reduzir custos. Afinal, ninguém duvida que as reprovações sejam aplicações ineficientes. De acordo com o Relatório da CEPAL (2000), foi registrado um salto significativo, quanto ao ingresso de estudantes nas escolas de ensino primário, na década de 1990, nos países latino-americanos, porém, a reprovação ainda demonstra a má gestão, a péssima aplicação financeira e a ineficiência da escola.

Mais uma vez, o que está em jogo é 'o para que e para quem serve', neste caso, a avaliação. Por isso, para o neoliberalismo o que falta à educação é o que fez tão bem ao mundo da empresa - a competição (Gentilli, 1998). E para os que crêem noutro mundo possível, o que falta é a participação dos atores que vivenciam os processos avaliativos e educativos, no sentido de, empoderados, comporem o pilar emancipação.

A avaliação, por isso, é um instrumento irrefutável para a qualificação das políticas educacionais, quando se dedica ao ato de reflexão sobre a prática escolar, na perspectiva de se refazer e requalificar. Isabel Alarcão (2007) aponta como função dos processos avaliativos, a realização de uma autocrítica e a partir daí, a tomada de decisões 
que resultem em novos fazeres, no sentido de aproximações ao objetivo inicial.

Moacir Gadotti (2000) usa uma metáfora interessante "ao puxar um fio, se acaba descobrindo uma malha complexa" (p. 87). Vamos desfazer a malha - "contexto educacional", quais os nós? Onde corre mais solta? Quem nos ajuda a desmalhar melhor e, por isso, é mais fácil desfazer a malha e puxar os fios?

O construto democrático se faz ao puxar o fio e desfazer a malha. É uma construção que se dá numa relação. Perceber os nós e refletir com o outro sobre eles, como desfazê-los faz parte da construção democrática. Portanto, a os processos avaliativos que estejam comprometidos com a aprendizagem e com a democracia, no sentido de gerar uma vida mais qualificada para tantos excluídos da cidadania, necessitarão reconhecer o outro e suas diferenças e com eles gerarão as possibilidades de tecer saberes e conhecimentos.

Afonso(2005)sedebruçaaoestudodaspolíticas contemporâneas da educação, enfatizando os meandros da avaliação educacional, a partir de uma análise essencialmente sociológica, enfocando nos testes estandardizados, utilizados pelos Estados Unidos e que servem de modelo para muitos países, seu foco de análise. A partir daí, emprega três conceitos de avaliação normativa, criterial e formativa.

A avaliação normativa parece ser a modalidade mais adequada quanto à competição e a comparação entre melhores e piores se tornam os valores fundamentais da educação. Medida a partir dos testes que se baseiam na correspondência a determinado padrão de desempenho estabelecido por critérios externos, atribuindo, geralmente, à origem social de estudante, seu grau de inteligência e, consequentemente, seu sucesso escolar. O que verificamos nesta modalidade é a dimensão de olhar o indivíduo sempre em relação ao outro (ibid).

Se for necessário que a avaliação educacional sirva "ao propósito de contribuir para a formulação de juízos equilibrados e para a tomada de decisões que incidirão diretamente sobre o aperfeiçoamento do processo" (Fonseca et alli, 2008, p. 33) de fato, a avaliação normativa está mais favorável para uma política regulada pelo mercado, do que para o fomento da participação e do empoderamento.

Já a avaliação criterial leva em conta muito mais as condições e os progressos daquele sujeito em relação a si mesmo, do que em comparação com os outros. Intensificando a transmissão do conhecimento e a aprendizagem mínima dos conteúdos necessários para o mundo do trabalho. Este modelo redimensiona o papel do Estado, tornando-o mais regulador do que o Estado Mínimo, mas por contar com a contribuição de empresários e da mídia, por exemplo, na definição das políticas educacionais, tornam-se um Estado-Avaliador (Afonso, 1999).

Vale observar que o estudo realizado por Afonso tem como objeto as avaliações estandardizadas aplicadas em alguns países desenvolvidos, que às vezes são fruto do baixo rendimento em exames internacionais prestados por estes países. E como o público só é bom quando controlado rigorosamente pela lógica do mercado - do privado (Apple, 1999), estas assim foram orientadas.

A avaliação criterial, por admitir um maior controle por parte do Estado, carrega um perfil de quase-mercado, pois surge com a proposição de, a partir dela, serem implantadas políticas originariamente empregadas em instituições privadas, para garantirem as melhorias necessárias (Santos, L. 2002).

Souza e Oliveira (2003) destacam o papel do Estado e sua noção de quase-mercado que fundamenta as "novas" políticas educacionais na perspectiva de responder as demandas surgidas com a tecnologia que requer um "novo" trabalhador e, consequentemente uma "nova" escola.

Descrevem seu objetivo principal na análise da avaliação do sistema educacional nas últimas duas décadas que possuem em seu escopo a qualidade que serve à naturalização da desigualdade e da competição, fortalecendo um neodarwinismo social, com predominância dos setores privados e de livre-mercado.

Ainda para Afonso (2005) há a avaliação formativa, que pode ser similar à avaliação criterial, quando beneficia aos alunos das classes mais favorecidas que retiram mais vantagens dos incrementos pedagógicos mais atuais em detrimento dos estudantes das classes populares, porém, de 
acordo com o autor, traz também a possibilidade de ruptura, pois o foco deste processo avaliativo é compreender onde estão os estrangulamentos de por que não ocorrem as aprendizagens, e isto, pode significar uma busca para sanear os problemas que dão origem aos problemas do ensino.

De um modo ou de outro cabe ressaltar que a avaliação, enquanto política de Estado, assume características e intenções muito distintas umas das outras. Há, portanto, que se realizarem estudos detalhados para compreender cada situação mais especificamente.

Trazendo novamente Almerindo Janela (ibid) que aponta para uma avaliação possivelmente emancipatória. "Um novo ponto de chegada, que não é mais, afinal, do que um outro ponto de partida para refletir a problemática da avaliação pedagógica..." (p. 125). Uma avaliação estruturada na base de relações de reciprocidade: de autonomia e de democracia.

\section{Conclusão}

$\mathrm{Na}$ intenção de compreender a avaliação de larga escala, enquanto uma política educacional inserida numa contextualização atual, é que realizamos o presente trabalho. Por isso, percebemos que tanto a avaliação normativa quanto a criterial são instrumentos utilizados pelo Estado, notoriamente o Estado neoliberal, muito mais para fornecer elementos capazes de sugerir uma regulação por parte do mercado para a educação, criando, consequentemente, possibilidades de privatização, favorecendo, no mínimo, as políticas de quase-mercado.

Como a avaliação educacional é elemento intransponível para as reflexões, os rearranjos e as recriações da educação, a avaliação formativa aparece como condição de que seja possível o envolvimento participativo dos atores realmente envolvidos, significando uma retomada do princípio da emancipação.

\section{Referências Bibliográficas}

Relatório CEPAL, 2000.

Caderno Lê Monde Diplomatique, Instituto Polis, janeiro de 2001.

AFONSO, A. J. Avaliação educacional: regulação e emancipação: para uma sociologia das políticas avaliativas contemporâneas. $3^{\mathrm{a}}$ ed. São Paulo: Cortez. 2005.

Estado, mercado, comunidade e avaliação: Esboço para uma rearticulação crítica. Educação \& Sociedade, Campinas, ano XX, n 69, dez./99, p. 139- 164

ALARCÃO, I. Professores Reflexivos em uma escola reflexiva. $2^{a}$ ed. São Paulo: Cortez, 2003. (Coleção Questões de nossa época).

APPLE, M. W. Se avaliar o professor é a resposta. Qual é a pergunta? In: VEIGA, I. P. A.; CUNHA, M. I. (org). Desmistificando a profissionalização do magistério. Campinas, SP: Papirus, 1999, p. 67-79. (Coleção Magistério: Formação e trabalho pedagógico).

BARROSO, J. O Estado, a educação e a regulação das políticas pública. Campinas: Educação e Sociedade. Vol. 26, no 92, out/2005. p. 1-13.

BOMENY, H. (Org.) Avaliação e determinação de padrões na educação latino-americana. Rio de Janeiro: Fundação Getúlio Vargas, 1997.

BONAMINO, A. C. Tempos de Avaliação Educacional: o SAEB, seus agentes, referências e tendências. Rio de janeiro: Quartet, 2002. (Coleção Educação e Sociedade).

CLARK, G. Política econômica e Estado. São Paulo: Estudos Avançados. Vol. 22, n 62, Jan./Abr, 2008, p 1-9. Dossiê Nação Nacionalismo.

COSTA, D. M. Política. In: STRECK, D. R.; REDIN, E.; ZITKOSKI, J. (org). Dicionário Paulo Freire. Belo Horizonte: Autêntica Editora, 2008, p. 325 - 328.

FRANCO, C. Quais as contribuições da avaliação para as políticas educacionais? FRANCO, C.; BONAMINO, A.; BESSA, N. (org). Avaliação da Educação Básica. Rio de Janeiro: PUC-Rio; São Paulo: Loyola, 2004, p. 45-63.

FONSECA, M.; OLIVEIRA, J. F.; AMARAL, N. C. Avaliação, desenvolvimento institucional e qualidade do trabalho 
acadêmico. In: FONSECA, M.; OLIVEIRA, J. F. (org). Avaliação Institucional: sinais e práticas. São Paulo: Xamã, 2008, p 21-35.

GADOTTI, M. FREIRE, P. GUIMARÃES, S. Pedagogia; diálogo e conflito. $3^{a}$ ed. São Paulo: Cortez: Autores Associados, 2000.

GENTILI, P. A. A. A falsificação do consenso: simulacro e imposição na reforma educacional do neoliberalismo. Petrópolis, RJ: Vozes, 1998.

MAINARDES, J. Abordagem do ciclo de Políticas: uma contribuição para a análise de políticas educacionais. Educação \& sociedade, Campinas, vol. 27, n 94, p. 47-69, jan./abr. 2006.

MELO, A. A. S. A mundialização da educação: consolidação do projeto neoliberal na América latina. Brasil e Venezuela. Maceió: EDUFAL, 2004.

MORIN, E. Os sete saberes necessários à educação do futuro. 2 ed. São Paulo: Cortez; Brasília: UNESCO, 2000.

2001

A cabeça bem-feita: repensar a reforma, reformar o pensamento. $5^{a}$ ed. Rio de Janeiro: Bertrand Brasil,

OLIVEIRA, D. A. As reformas educacionais e suas repercussões sobre o trabalho docente. In: OLIVEIRA, D. A. Reformas Educacionais na América Latina e os trabalhadores docentes. Belo Horizonte: Autêntica, 2003, p. 1337.

PARO, V. H. Administração escolar; Introdução crítica. 11 ed. São Paulo : Cortez, 2002.

RAMPINELLI, W. J. A Globalização e as Privatizações. In: FERREIRA, A. C. e ALVIN, V. A Trama da Privatização A reestruturação neoliberal do Estado. Florianópolis: Insular, 2001.

SANTOS, B. de S. Para um novo censo comum: a ciência, o direito e a política na transição paradigmática. $3^{\mathrm{a}}$ ed. São Paulo: Cortez, 2001. Vol. 1. A crítica da razão indolente: contra o desperdício da experiência.

SANTOS, L. L. C. P. Políticas Públicas para o Ensino Fundamental: parâmetros curriculares nacionais e sistema nacional de avaliação (SAEB). Educação e Sociedade. Campinas, Vol. 23, n’ 80, set./2002, p. 346-367.

SHIROMA, E. O. et alli. Política educacional. Rio de Janeiro: DP\&A, 2000.

SMITH, A. A riqueza das nações: investigação sobre sua natureza e suas causas. São Paulo : Abril Cultural, 1983. Coleção Os Economistas.

SOUZA, S. Z. L. \& OLIVEIRA, R. P. Políticas de avaliação da educação e quase mercado no Brasil. Educação e Sociedade. Campinas, Vol. 24, n 84, set./2003, p. 873-895. 